\title{
Apuntes sobre la locura en el Virreinato del Perú.
}

\author{
Notes on the madness in the Viceroyalty of Peru. \\ Santiago Stucchi-Portocarrero ${ }^{1,2, a}$
}

\section{RESUMEN}

La locura en el Virreinato del Perú fue explicada tanto en términos médicos como sobrenaturales. La medicina se basó principalmente en la teoría de los cuatro humores. Para denominar la locura y sus diversas formas de manifestarse se utilizaron términos tales como falta de juicio, insania, demencia, melancolía, manía y otros, con significados no equivalentes a los actuales. El cuidado de los locos estuvo en manos de los médicos, la familia o los religiosos. La Santa Inquisición debió determinar si los procesados se encontraban o no en su sano juicio, recurriendo a diferentes estrategias ante los casos dudosos, incluyendo la opinión de los médicos. La psiquiatría surgió en el Perú mucho después de la era virreinal, y sus intentos para explicar la locura en aquellos tiempos llevaron por un lado a una valiosa recolección de información, sobre todo por parte de Hermilio Valdizán y Óscar Valdivia Ponce, y por otro lado a la elaboración de diagnósticos retrospectivos, que ilustran sobre el discurso nosológico de sus expositores. En los últimos años las opiniones psiquiátricas sobre el periodo virreinal se han centrado en la figura de Santa Rosa de Lima, llevando a planteamientos variopintos. Los diagnósticos retrospectivos se sustentan en premisas cuestionables, tales como atribuir una naturaleza transhistórica y transcultural a los trastornos mentales y a la idea de normalidad, así como creer que existen fuentes históricas fidedignas que reflejan la verdad de los hechos.

PALABRAS CLAVE: Historia de la medicina, enfermos mentales, Perú, psiquiatría, trastornos mentales (Fuente: DeCS BIREME).

\section{SUMMARY}

Madness during the Viceroyalty of Peru was explained both in medical and supernatural terms, The medicine was based mainly on the theory of the four humors. To name madness and its various forms of manifestation were used terms such as lack of judgment, insanity, dementia, melancholy, mania and others, with meanings not equivalent to the current ones. The care of the insane was given by doctors, family or clergy. The Holy Inquisition had to determine whether the defendants were mentally sane or not, resorting to different strategies in the doubtful cases, including the opinion of the doctors. Psychiatry emerged in Peru long after the Viceregal era, and its attempts to explain the madness of those times led to the gathering of valuable information, especially by Hermilio Valdizán and Óscar Valdivia Ponce, and, on the other hand, to the formulation of retrospective diagnoses, which illustrate the nosological discourse of its speakers. In recent years, psychiatric opinions on the viceregal period have focused on the figure of Saint Rose of Lima, leading to varied approaches. Retrospective diagnoses are based on questionable premises, such as attributing a transhistorical and transcultural nature to mental disorders and normality idea, as well as believing that there are reliable historical sources that reflect the truth of the facts.

KEYWORDS: History of medicine, Mentally Ill persons, Peru, psychiatry, mental disorders (Fuente: DeCS BIREME).

\footnotetext{
Facultad de Medicina Alberto Hurtado, Universidad Peruana Cayetano Heredia. Lima, Perú.

2 Hospital Víctor Larco Herrera. Lima, Perú.

a Médico psiquiatra.
} 


\section{INTRODUCCIÓN}

El Virreinato del Perú se instaló oficialmente en 1542, lo que inauguró un extenso periodo de casi tres siglos, caracterizado por la autoridad absoluta del monarca español, simbolizada en la figura del virrey, así como el gran poder de la Iglesia católica, en medio de una sociedad rígidamente estamental y profundamente devota (1). La medicina que llegó de España estaba fuertemente influida por las enseñanzas de Hipócrates y Galeno, pero también por la medicina árabe, representada por Avicena, Rhazés y Albucasis; tal influencia se vio mermada a partir del siglo XVIII, con el arribo de la Ilustración europea (2). A lo largo de todo ese tiempo -y como ha sido en todos los tiempos y lugares-, la sociedad colonial conoció periódicamente personas con actitudes y discursos extraños e incomprensibles; a aquéllas se les llamó locos, faltos de juicio, lunáticos, vesánicos, amentes, dementes, melancólicos, maniacos, furiosos, insanos, bobos, tontos, fatuos, etc., y se les consideró víctimas de desequilibrios de los humores, enfermedades nerviosas, pasiones fuera de control, hechicería o posesión diabólica. Fueron algunos de ellos cuidados por su familia, y otros encerrados en los conventos o las loquerías.

El presente artículo está dividido en cuatro secciones. En la primera se verá cuáles fueron las ideas que se tenía en los tiempos virreinales acerca de la locura, para lo cual se revisarán testimonios de la época, con el apoyo de diccionarios y otros textos afines. En la segunda sección se citarán algunos procesos llevados a cabo por la Santa Inquisición contra personas cuya cordura fue puesta en tela de juicio, para conocer los argumentos que decidieron finalmente por la absolución o la condena. En la tercera parte se hará una descripción de cómo concibieron los psiquiatras historiadores del siglo XX a la locura de los tiempos virreinales, bajo su propio marco nosológico y nosográfico. Y en la cuarta sección se discutirá sobre los diagnósticos psiquiátricos retrospectivos, en particular los que han proliferado últimamente en torno a la figura de Santa Rosa de Lima.

Siguiendo una línea historiográfica que cuestiona el carácter "transhistórico" de los trastornos mentales y del conocimiento en torno a ellos, se ha evitado hacer comparaciones entre las expresiones de locura de los tiempos virreinales y los diagnósticos psiquiátricos actuales, método habitual en la narrativa histórica clásica de la medicina y la psiquiatría, imperante hasta la década de 1960; a tal visión no se le resta importancia, más bien se le valora en su contexto. El nuevo enfoque ha sido ensayado por otros autores, que escribieron sobre la locura en los virreinatos de Nueva Granada y Nueva España, como se verá más adelante. Por otro lado, creemos que el presente es el primer texto que, desde la misma psiquiatría, intenta analizar la forma cómo los psiquiatras historiadores peruanos se aproximaron al fenómeno de la locura de los tiempos antiguos. Definitivamente muchas cosas quedarán sin ser incluidas en este breve escrito; esperamos que futuros textos amplíen con creces -o inclusive corrijan de ser necesario- lo ahora expuesto.

El tema de los asilos para locos, ligado evidentemente al de la locura, ha sido tratado en otra publicación nuestra (3), por lo que no se mencionará aquí.

\section{LAS IDEAS SOBRE LA LOCURA EN LOS TIEMPOS VIRREINALES}

El Diccionario de Sebastián de Cobarruvias, de 1611, de importante presencia en el mundo colonial hispanoamericano (4), define al loco como "el hombre que ha perdido su juyzio", haciendo la analogía con los vocablos latinos "insanus, vaesanus, amens, demens, furiosu", en tanto que la locura es descrita como "insania, dementia, \& c. Loquear, hazer locuras, o burlarse, y holgarse descompuestamente" (5). Aclara el mismo libro que "Entre loco, tonto, y bovo ay mucha diferencia, por causarse estas enfermedades de diferentes principios y calidades. La vna de la colera adusta, y la otra de la abundancia de flema" (5). Por su parte, el Diccionario de la Real Academia Española de 1780 define al loco como "El que ha perdido el juicio, carece de razon, y hace y dice disparates", y a la locura como "Enfermedad que priva del juicio, y embaraza el uso de la razon", estableciendo la equivalencia con las palabras "Furor, insania, dementia" (6).

La locura, en consecuencia, era entendida como una enfermedad, cuyas causas tenían que ver con debilidad del cerebro, desequilibrio de los cuatro humores (sangre, flema, bilis amarilla / cólera y bilis negra / melancolía), mala alimentación, desventuras, pasiones fuera de control o cuestiones sobrenaturales (7). No existía en aquel entonces la idea de "enfermedad mental" como se entiende ahora, pues la obnubilación del juicio tenía un origen somático, al ser el alma - psyche- de naturaleza divina, y por lo tanto incorruptible; era pues el cuerpo el que enfermaba y perturbaba la expresión del alma $(8,9)$ (el mismo diccionario de 1611 definía "mental" como "cosa que 
pertenece a la mente, y al alma") (5). Hasta el siglo XVIII, la locura no admitía presentaciones parciales, de modo que solo cabía la alienación o la cordura en formas absolutas (10), pero sí se reconocían intervalos de lucidez; de ahí que se identificara al "loco atreguado" como el que hacía "treguas con la locura", en contraste con el "loco perenal", que "perpetuamente perseuera en su locura" (5). La locura podía ser también consecuencia del pecado, y devenir por lo tanto en motivo de vergüenza ante Dios, como se puede ver en la figura 1 .

La explicación médica humoral no se oponía a los discursos sobrenaturales, imperantes en los tiempos virreinales. Así, Fray Antonio de la Calancha brinda la siguiente descripción en su "Coronica moralizada" de 1639 (Libro Segundo, Capítulo XXXVII): "El año pasado de 1631, un noble idalgo, llamado Alonso de Astudillo", que "desestimò sienpre a los Sacerdotes, i onrava poco a los Religiosos. (...) fuese apoderando el Demonio de su imaginativa, porque le quitaron la governacion, i apuravale con que se aorcase; conociose el infernal impulso, i vivia cuydadosisima su familia porque no le ejecutase (...). Vna mañana aviendo ido a Misa su mujer, se encerrò en una quadra de su casa, adonde vieron entrar los criados dos personas desconocidas, i cerrar las puertas del aposento. Bolviendo su muger lo allò aorcado de una viga (...) i llegandolo a entender el Obispo (...), le mandò quemar el cuerpo, porque asi lo mandan las Sinodales, con que castigò Dios al enemigo de los Sacerdotes" (11).

No expresa mucha duda Fray Calancha sobre el origen demoniaco del suicidio del gobernador (aunque no se puede descartar la posibilidad de un asesinato a manos de los dos desconocidos), quizás influido por la animadversión de aquél hacia los religiosos, o porque de otro modo no podría ser explicado semejante proceder en quien por lo demás no daba muestras de locura. De todos modos menciona el cronista la pérdida del cargo como incentivo para la muerte autoinfligida, así sea con la intermediación del Diablo. Se extiende entonces la comprensión del suicidio más allá de lo netamente místico, y se le reconoce adicionalmente como una reacción ante la adversidad.

Este mismo pasaje ilustra acerca de la condena eclesial hacia el suicidio, que obligó al Obispo al castigo del cuerpo inerte de Don Astudillo. Tal tradición se sustentaba en lo dicho siglos antes por San Agustín en su De civitate Dei (Libro I, Capítulo $\mathrm{XX}$ ): "No existe autoridad alguna que conceda a los cristianos, en cualquier caso, el derecho de quitarse a sí propios la vida voluntariamente" (12), y adicionalmente en lo expresado por Santo Tomás en su Summa Theologiae (Parte II-II, Cuestión 64, Artículo 5): "Es absolutamente ilícito suicidarse" (13).

También en el siguiente caso reportado por el Padre Calancha, un factor contextual desembocó en la locura (Libro Tercero, Capítulo XXIII). Fray Pablo de Castrovi había abandonado la administración del pueblo de Paria, y "por aver cooperado en la dejacion, cargò de manera en este escrupulo (...) que rindiendole la pena i la melancolia, perdio el juizio i estuvo loco veynte años. Era su locura callar, de manera, que en uno y dos años no alçava los ojos del suelo pensativo, i si ablava algo, era decir que contra conciencia avian dejado las comunidades de Paria" (11). Habiéndose inundado su habitación "por averse roto una acequia", Fray Castrovi "salio al dormitorio dando grandes vozes, (...) i entrando un Religioso a decir al celdero, que tenia cuidado del Padre fray Pablo, que ya avia vuelto a su juizio i ablava cuerdo, devoto i jovial" (11).

En otros casos, fue la ignota voluntad de Dios la presunta causa de la locura, al menos en principio, como se puede leer en el siguiente párrafo, también de Fray Calancha (Libro Tercero, Capítulo XXIX): El "Padre fray Francisco Bezerra (...) era tan constante en la oracion, que se la pasavan las noches orando; i estas vigilias con grandes ayunos le desflaquecieron tanto, que (...) perdido el juizio (secretos de Dios) siendo furioso con las Lunas su acidente, en lo fuerte de sus locuras, decia dulces requiebros a la Madre de Dios, de quien fue devotisimo (...). Quando acavaba el acidente con mudança de Luna, preguntava, si avia dicho algo contra Dios o su Madre? Si le decían que si, se dava crueles golpes en la boca i en los pechos, $i$ decia: Suzio blasfemo a un Dios infinito os atreveys, i a la Madre de Dios? Bien pagays las mercedes que os aze; tomad bestia desbocada, i moliase a golpes el cuerpo, i quedaba llorando por grandes ratos. (...) En el convento nuevo de Lima le tuvieron curando, i bolviole Dios algunos dias antes de morir tan entero el juizio, que todas sus palabras, discursos i acciones eran provechosas i nacidas de un santo amor (...). Locura dichosa, falta de juizio conveniente para llegar cuerdo al juizio de Dios" (11).

Aunque el cronista delega en los "secretos de Dios" el origen de la insania de Fray Becerra, alude asimismo a los desvelos y ayunos en los que ponía mucho empeño (recordándonos brevemente al ingenioso hidalgo que "del poco dormir y del mucho leer se le secó el celebro") (14). Contrariamente al penoso final 


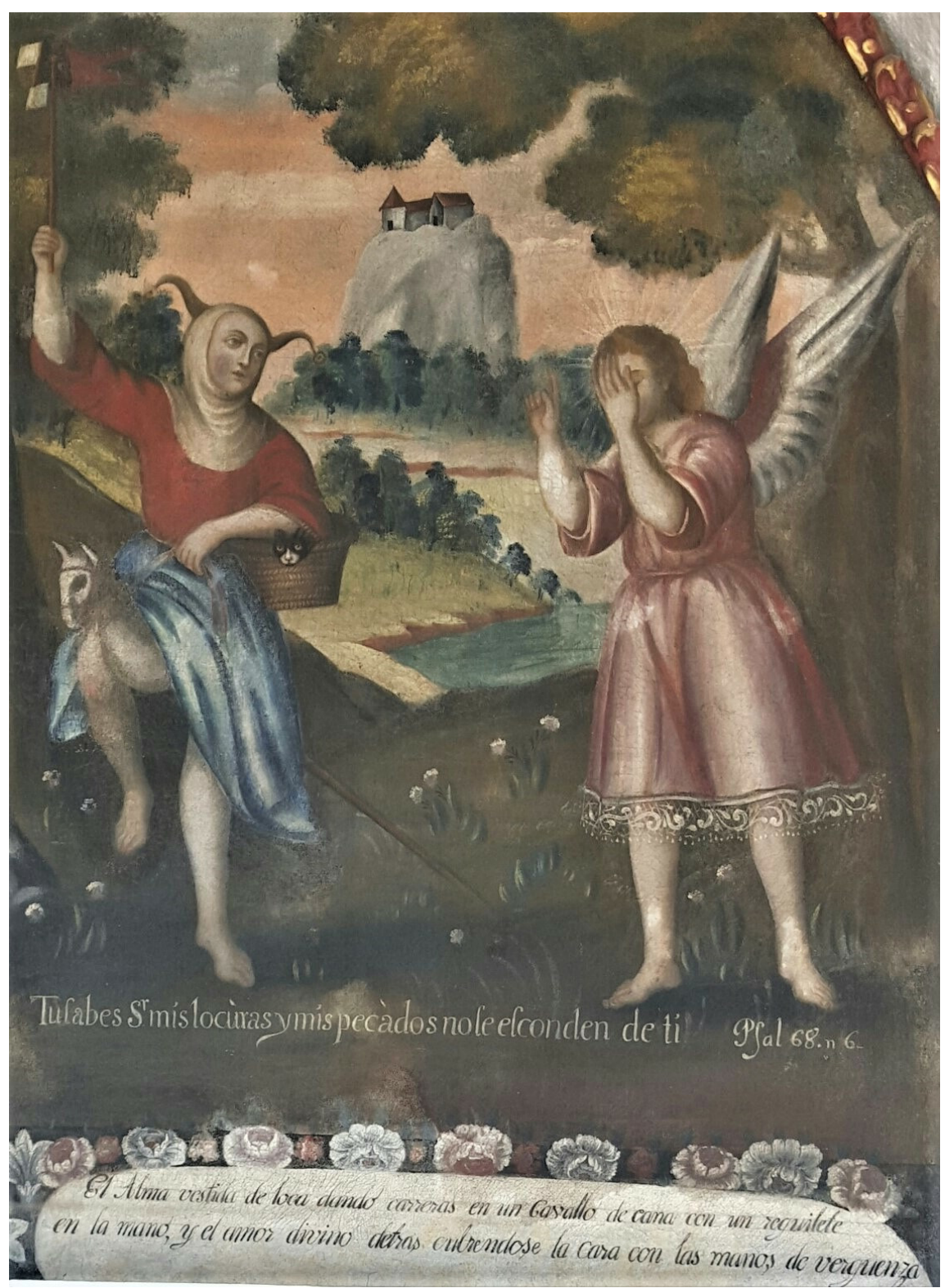

Figura 1. Pintura mural del siglo XVIII en el Convento de Santa Catalina, Arequipa, Perú. Dice la leyenda: "Tú sabes Señor mis locùras y mis pecàdos no se esconden de ti (Salmos 68 n 6). El Alma vestida de loca dando carreras en un Cavallo de cana con un reguilete en la mano, y el amor divino detras cubriendose la cara con las manos de verguenza". (Foto del autor).

del gobernador Astudillo, la locura de Fray Becerra terminó siendo "dichosa" y "conveniente" en el camino hacia la salvación. Asimismo, es de notar la influencia de la luna en la locura, origen del término "lunático". El Diccionario de Cobarruvias dice lo siguiente: "LVNA, (...) Prouerbio: Estar la luna sobre el horno, se dize del loco, quando està con furia, que ordinariamente es en luna llena: y alli se toma horno por la cabeça del hombre, que es como vna hornaza: y entonces le hiere de lleno. Por esta razon se llamaron Lunaticos los faltos de juizio, que con los quartos de luna alteran su accidente" (5).
En otro pasaje de la "Coronica" (Libro Tercero, Capítulo XIX), Fray Calancha nos deja en claro que su visión religiosa no le impedía aceptar explicaciones netamente médicas y ajenas a lo sobrenatural para los extravíos de la razón: "Suelen tener por verdades éstas apariencias los enfermos de locura lupina, que los Arabes llaman Chatrab, i los Latinos melancolia confirmada; i estos tales aun sin engaños del Demonio burlada la fantasia, piensan que son i se imaginan perros, leones, toros i otras bestias; (...) i asi se à de examinar primero al que dice que mira estas figuras, o se persuade a ellas, si padece esta enfermedad 
melancolica o locura lupina; porque ni esto entra en la ciencia magica, ni tiene parte el Demonio, sino la flaqueza del celebro, o la dolencia i enfermedad de los umores" (11).

Se ilustra aquí también el concepto de melancolía como una forma de locura que lleva a quien la padece a imaginarse transformado en animal, de lo que deriva el término "locura lupina" o "licantropía", haciendo alusión al hombre convertido en lobo. La locura lupina tiene a su vez relación con la influencia selénica, mencionada antes. En el Diccionario de la Real Academia de 1780 encontramos la siguiente definición: "MANÍA LUPINA. Cierta especie de melancolía, con la qual el que la padece suele salirse de casa de noche, $\mathrm{y}$ andar alrededor del lugar hasta el amanecer en quatro pies como los brutos, y aullando como los lobos. Busca las sepulturas y saca y despedaza los cadaveres, y de dia huye de los vivos. Algunos muerden como los perros" (6). En teoría, debía distinguirse entre la licantropía como enfermedad, y los casos de auténtica transformación zoomorfa, en los que se asumía la intervención del Demonio (8).

Fue el concepto de melancolía bastante amplio en realidad, si se lee la definición del Diccionario de Cobarruvias: "enfermedad conocida, y passion muy ordinaria, donde ay poco contento y gusto (...). Pero no qualquiera tristeza se puede llamar melancolia en este rigor; aunque dezimos estar vno melancolico, quando està triste y pensatiuo de alguna cosa que le da pesadumbre" (5). Robert Burton, en su "Anatomía de la melancolía”, de 1638 (Parte 1, Sección 3), refirió que "algunos signos son secretos, algunos manifiestos, algunos en el Cuerpo, algunos en la mente, y varían de manera diversa, según las causas internas o externas (...). (Los síntomas) llegan a ser infinitos (...). (Los melancólicos) están preocupados por escrúpulos de la conciencia, desconfían de las misericordias de Dios, piensan que irán al infierno, el diablo los poseerá y tendrán gran lamentación (...) creen que son de cristal, y que, por lo tanto, ningún hombre debe acercarse a ellos; o que son como el corcho, o tan ligeros como las plumas; otros tan pesados como el plomo; algunos temen que sus cabezas caigan de sus hombros, o que tengan ranas en sus vientres" (15). El origen era humoral, según dice Fray Agustín Farfán en su "Tratado breve de medicina", de 1592 (publicado en México) (Libro Segundo, Capítulo Sexto): "Dos maneras ay de melancolia, la vna se haze de las hezes de la sangre. $\mathrm{Y}$ à esta llaman melancolia natural, y es fria y seca. La otra se haze de colera, que con el demasiado calor se queze y requema. A esta llaman colera negra, ò melancolia adulta, aunque hablando con rigor, no es propiamente melancolia. (...) El mienbro que mas padece del cuerpo en esta enfermedad, es el celebro, y no el coraçon, como algunos piensan" (16).

La melancolía de los siglos XVI-XVII era entonces un estado que alternaba entre la aflicción y la pérdida del juicio, o que conjugaba ambas, sumándose a ello toda clase de padecimientos físicos. En el mundo occidental cristiano de aquellos tiempos, la culpa fue un elemento importante de la melancolía, incitada por la idea del "pecado original", y lo sobrenatural podía manifestarse cuando Dios castigaba con tal padecimiento por algún pecado, cuando la dolencia era en sí misma una prueba para alcanzar la pureza, o si Satanás aprovechaba la debilidad melancólica para poseer el cuerpo (17); después de todo, el maligno tenía predilección por el humor melancólico (8).

El Diccionario de 1780 definió la melancolía como: "Tristeza grande y permanente, procedida de humor melancólico, que domina y hace que el que la padece no halle gusto, ni diversion en cosa alguna" (6), dejando todavía en claro el origen humoral. Fue recién en la segunda mitad del siglo XIX que el concepto de melancolía se limitó del todo a lo pasional o "afectivo", lo que conserva hasta hoy (18).

La histeria fue concebida desde la Antigüedad como la consecuencia de una matriz que se movía caprichosamente dentro del cuerpo de la mujer, generando dolencias de toda índole (19). Las descripciones médicas virreinales no fueron ajenas a esta idea. En México, Farfán dedicó un capítulo de su "Tratado" al "mal de madre" (Libro Primero, Capítulo Once): "Si la sangre corrompida esta mesclada con cólera requemada, causa con el mal de madre vna manera de pasmo y encojimiento de los neruios. Y si este humor sube al celebro causa pasmo vniuersal (...). Quando la sangre corrompida esta mesclada con melancolia y sus vapores suben al celebro, causan muy grandes tristezas, y algunas vezes vna manera de locura" (16). En el Perú, Francisco Bermejo y Roldán relata lo siguiente en su obra sobre el sarampión, de 1694 (Capítulo VII): "Hace tambien experimentado en esta epidemia las muchas ansias y bomitos, que especialmente suelen acaecer en las mugeres, padeciendo vnas pasiones procedidas de la madre, que llamamos pasiones hystericas, poniendo à algunas en tal aprieto, que parece que se ahogan, enfriandose, y con retiro de pulsos; à otras quitandoseles el habla por passion de el coraçon. Y para socorro de accidente tan penoso, es necessario valerse de vna muger, que con 
toda suavidad, con las dos manos le atraiga la madre a su lugar, que es el ombligo" (20).

La violencia desatada por el "loco furioso" en los tiempos virreinales obligaba a la reclusión en las "casas de locos" o "loquerías", de las cuales la más reconocida era la del Hospital Real de San Andrés, fundado a mediados del siglo XVI (3). De tales lugares se esperaba no solo el albergue de los enfermos, sino además su curación, como se lee en el Diccionario de Cobarruvias, de 1611: "Casa de locos es el hospital donde los curan" (5). Pero muchas veces la intención del encierro no iba más allá de la contención, como explica el mismo texto: "FVRIOSO, muchas vezes se toma por el loco, que para assegurarnos del es necessario tenerle en prisiones, o en la gauia (...) no ay que esperar mas para atarle. (...) GAVIA (...) a los locos furiosos los tienen en vnas jaulas de palo: y a estas tambien llaman gabias" (5).

Se encuentra algo adicional sobre tal asunto en el siguiente párrafo de los "Tesoros verdaderos" de Fray Juan Meléndez, de 1681 (Tomo Tercero, Libro IV, Capítulo XXX): “( ...) cayò muy malo Iuan de Villa, y se entendio, que le auian hecho mal, porque perdio totalmente el juicio, y dio en furioso (...), le lleuò a la loqueria del Hospital de San Andres, paraque alli le curassen (...). Durole siete meses la locura à Iuan de Villa, y no tenia remedio, antes iba siempre à mas, con que era necesario tenerle en vn cepo, y atadas las manos, porque hacia pedaços los vestidos (...). Luego, que vio a la muger le pregunto, que donde estaua, que porque le auian traydo allí, y le tenían preso, como à malhechor en vn cepo? Ella le respondio, que porque auia estado muy malo de vna enfermedad peligrosa" (21).

En el siglo XVIII llegaron al Perú las ideas de la Ilustración europea; la escolástica y la ortodoxia aristotélica fueron refutadas, introduciéndose otras doctrinas filosóficas, como el racionalismo, el empirismo y el sensualismo, y en la medicina se desarrollaron nuevas teorías médicas que terminaron reemplazando a la humoral $(22,23)$. En este contexto, Juan Lastres describe en su "Historia de la medicina peruana" (Capítulo XXXIV) el caso de un tal M.C., que asesinó al Presidente de la Audiencia del Cusco en 1798; un médico apellidado Justiniani publicó entonces "un curioso documento médico legal", en el que atribuyó el crimen a la locura de M.C., explicando que "el cerebro de los maniaticos es duro, friable y flavo, sus vasos constreñidos varicosos y llenos de una sangre negra; de donde se infiere ser la agitacion de los liquidos del cerebro la causa inmediata de la mania" (2).

La Ilustración llevó a la fundación de la "Sociedad Amantes del País" y de la publicación periódica "Mercurio Peruano" (2). Justamente en el quinto número de esta revista, de 1791, apareció un artículo titulado "Manias particulares", que retrata a tres personajes pintorescos de aquellos tiempos: Don Diego Lopez Gonzalez de la Peña, autoproclamado "Alcides de la Geografía, y monstruo de las Matemáticas", quien dirigió al Virrey Francisco Gil y Lemos una carta exigiendo un justo reconocimiento por haber descubierto "la quadratura del Círculo"; Don Manuel de Torquemada, quien anunció haber creado una máquina, a la que llamó "Molinete", pero "que no era más que una piedra", con la cual "empedraria de barras las calles de toda la Capital", y finalmente Don N. Montero, "que trabajó treinta años en desenterrar un tesoro" que jamás encontró (24).

El Diccionario de 1780 considera dos significados para el vocablo "manía": "Enfermedad de la fantasía que la altera y desordena, fixándola en una especie sin razon, ni fundamento", y: "Extravagancia, capricho, tema, y ridiculez de genio; y así se dice: ha dado en la MANÍA de que ha de hacer esto" (6). Vemos así que la primera de las definiciones hace referencia a la enfermedad, a una forma de locura, en tanto que la segunda se usa para designar a quienes se empecinan con algunas materias en forma necia, sin ser obligadamente carentes de razón; este segundo significado sobrevive hasta ahora unido al calificativo "maniático", y es al parecer el que utilizó el autor para referirse a los tres curiosos protagonistas del relato anterior. El concepto de manía como enfermedad se vio reducido a lo afectivo a partir del siglo XIX, tal como sucedió con la melancolía (18).

Según parece, la Ilustración influyó también en Santiago de Cárdenas. En 1761, este lector de Voltaire, Moreri y Feijoo redactó un documento sobre el vuelo del cóndor, en el cual propuso un mecanismo para permitir el vuelo humano, y lo envió al Virrey Amat y Junyent. El trabajo fue calificado como "inútil y ridículo", y su autor tildado de loco (25), a lo cual él respondió con un extenso escrito, del cual extraemos lo siguiente: "Se me a dicho que es freneci solo en pensar en tal y que presto dare en Loco (...). Locura Grande es torear por la procimidad que en el Acto si de perder la Vida pues es sierto que por diestro que sea el Toreador no dejando el oficio muere en el y lo que 
debe causar lastima se ase risa (...). Locura es tomar la locura por sus manos con noble riesgo de su salud Alma y onra. Cordura el Bino por Birtud y nesesidad. (...) Locura Grande es siendo medico curar solo con la mira del Interes curar sin especulativa y no saber o no atender a las osilaciones del pulzo sino solo a la mada o buena capacidad del enfermo. Cordura es curar poniendo de su parte tienpo i obserbacion. (...) Locura Grande es comer mucho por que de tal se ase el onbre Bruto peca contra la consiencia y el peligro de una propisia cordura es comer conforme a lo discreto, para mantenerse y no para yncharse (26). Esto muestra que tanto para los que hicieron mofa de "Santiago Volador" -apelativo que recibió Cárdenas-, como para él mismo, la locura estuvo definida por los actos insensatos o incomprensibles, e inclusive por el solo pensar seriamente en ellos.

En su obra "Observaciones sobre el clima de Lima”, de 1806, Hipólito Unanue escribió lo siguiente: "Enfermedades del ánimo (...). Un cielo nebuloso ofreciendo las ideas con un ayre opaco, introducirá las semillas de los sentimientos melancólicos. Mucho mas si la imaginación es sensible, y delicados los nervios: porque entónces las impresiones se hacen completas, y se retienen con tenacidad (...). Considero á la melancolía como un efecto de debilidad corporal. Parece originarse de una persuasion interior de nuestra impotencia. Así se excita á la vista de los túmulos, y las ruinas que nos recuerdan lo efímero de la vida: á presencia de los grandes lagos, riscos y precipicios, porque nos consideramos sin fuerzas para salvar el peligro, si cayéramos en ellos" (27).

La melancolía ha sido ahora claramente situada por Unanue entre las "enfermedades del ánimo", diferenciándola del concepto racional de la locura. La génesis de aquella dolencia la explica el futuro Protomédico General aludiendo a la impresión de los sentidos sobre un sistema nervioso debilitado que, como consecuencia, genera contenidos imaginativos mórbidos, un postulado que recuerda a la filosofía empirista de David Hume (28). Pero también recurre Unanue a factores internos para explicar la melancolía: "Los órganos de la digestión son el sitio principal de esta debilidad; por eso los antiguos filósofos colocaban en la boca superior del estómago el asiento del alma (...). De aquí se levantan los negros vapores que eclipsan la claridad de la razón; los fantasmas extraños, amargo sustento de la imaginación; la muerte austera que va tirando continuamente del dogal. Aquí está el negro buytre, devorando las entrañas del infeliz Prometeo" (27).

Esto último va de la mano con el concepto de afección vaporosa, "un vicio general ó particular del genero nervoso, producido por el encogimiento ó arrugacion de las fibras nervosas. Se llama hystérico en las mujeres, porque los antiguos miraron á los diferentes desórdenes del útero, por causa de estas enfermedades. Llamase hypocondriaco ó melancólico en los hombres, porque los mismos Autores establecieron su causa en los hypocondrios y vísceras del vientre inferior" (29). Se trata pues de una enfermedad corporal en el sentido completo del término, que da manifestaciones a todo nivel. En el caso de la hipocondría, la define el Diccionario de 1780 como: "melancolía suma, y otros efectos que atormentan al sugeto; como son dolor de estómago, flatos freqüentes, vómitos, opresión del pecho, dificultad en respirar, falta de sueño y otros que refieren los médicos" (6).

\section{LOCURA E INQUISICIÓN}

El Tribunal del Santo Oficio de la Inquisición fue fundado en España en 1478, y en 1570 comenzó a funcionar el Tribunal de Lima, con el propósito de favorecer "al augmento de nuestra santa fé católica, deseando la ampliacion y propagacion de la religion christiana, y que las dichas provincias por Dios á Nos encomendadas, sean libres e preservadas de todo error y sospecha de toda heregía" (30). Ya desde 1503 el Directorium Inquisitorum había advertido lo siguiente: "Sucede á veces que por librarse de la tortura se fingen locos los reos, pero si se presume que es fingida esta locura no se ha de dejar de darles tormento, eso mas que asi se conoce si es demencia fingida ó efectiva, y cuando hay otros indicios no es malo hacer la prueba atendido á que no resulta de ella peligro de muerte" (31).

Quedaba pues claro para el Santo Oficio que la locura eximía de culpa (al menos en teoría), pero el discernimiento entre locura y razón no siempre fue sencillo de resolver, por lo que los inquisidores solían recurrir a estrategias tales como colocar un acompañante junto con el convicto o espiar a través de agujeros secretos, y solo ocasionalmente pedir la opinión de los médicos (32), quedando siempre el recurso de la tortura, para la cual no había mayores reparos. El "diagnóstico" de la locura no era pues privativo de la medicina, sino que podía ser hecho por cualquier funcionario. Las dudas y los manejos en torno a la presunta locura de los reos han sido descritos también en los procesos del Tribunal en el Virreinato de Nueva España $(7,33)$, en el Virreinato de Nueva Granada (34) y en la Metrópoli (32).

El primer caso representativo en el Virreinato del 
Perú se encuentra en el proceso seguido contra Mateo Salado (transcrito en el Capítulo IV de la "Historia de la Inquisición de Lima" de José Toribio Medina). Era aquél un francés "que estava en esta ciudad y andava muy maltratado y abia casi diez años que andaba cabando en una guaca que es un enterramiento de yndios que está cerca desta ciudad a do dizen la Madalena, el qual pública y comunmente estava avido y tenido por falto de juicio, entre todos los que le conocian, por verle andar tan destraydo, y travajando solo y en bano en aquella guaca" (30). Salado fue hecho preso en un primer momento por una serie de supuestas blasfemias proferidas contra la Iglesia, pero "paresciendo que era loco se mandó sobreseer", hasta que fue nuevamente encausado, entre otras cosas por afirmar "que no se an de adorar las ymágenes ni reberenciallas (...) y que avia de aver frayles ni monjas ni clérigos, que comian la renta de la iglesia (...), que comian el sudor de los pobres (...) y que ningun honbre que vendiese negros y mulatos se podria yr al cielo sino que yba condenado al infierno, y que el papa que lo consentia era un borracho" (30). De esta segunda prisión no salió bien librado, siendo condenado y ejecutado en 1573.

Para la Santa Inquisición, Mateo Salado demostró estar en sus cabales, pues: "Sabe mucho del testamento nuebo de Coro y alega a cada cosa con su autoridad tomada del dicho testamento: tiene como esta dicho muy buen juizio y entendimiento y cuanto a que esta preso no se a entendido del cosa en contrario, sino que como él andava diziendo estas heregías tan claras y manifiestas y cavaba en aquella guaca solo las personas que se lo oyan lo atribuyan a locura, pero realmente él no es loco, sino herege pertinaz" (30). La capacidad para conocer la palabra de Dios y argumentar debidamente bastó para descartar la posibilidad de locura, que era, como se vio antes, la pérdida completa de la razón; estando así, con plena capacidad de entendimiento, no se podía librar del castigo. Para Teodoro Hampe, Mateo Salado en efecto no fue un enajenado, sino un migrante de religión luterana "que cayó a niveles de pobreza extrema y subsistía investigando, buscando objetos del mundo ritual andino, lo cual fue transformado por el vulgo en actos de brujería", y fue la defensa firme de su fe lo que le convirtió finalmente en la "primera víctima de la Inquisición de Lima" (35).

Otro caso ilustrativo fue el de Francisco de la Cruz (Capítulo V de la "Historia"), sacerdote franciscano que fue procesado por haber "hereticado i apostatado de Dios, diciendo, teniendo, creyendo i afirmando, enseñando i dogmatizando a otros muchos, herejías formales", haber "hecho pacto con dos demonios para aprender el arte májica", y porque "habia declarado a muchas personas que para poder plantar su nueva secta, habia de nacer en Lima un niño, destinado a ser santo i gran siervo de Dios, capellan de Nuestra Señora i otro Job en paciencia, fraile de Santo Domingo i remedio del Perú" (30). Ante tales acusaciones, Fray De la Cruz "se manifestó persuadido de que no tenia para que ocultar lo que a su juicio era verdadero", mas como "los testigos comenzasen a decir que hacia desatinos i cosas hechas de hombre fuera de juicio", como "dijo cantidad de palabras feas contra el Santo Oficio i otras nefandas i deshonestísimas", y además "por hallarse mui melancólico se le quitó un cuchillo, con temor de que pudiera suicidarse, i para ver si estaba realmente loco, ocurrieron los Inquisidores al singular arbitrio de que se le pusiese un par de grillos (...). Llamóse despues al médico, i con su informe i el de testigos, se le declaró sano i cuerdo. (...) (A uno de los jueces) le parece que no está loco sino en su juicio, como ántes lo estaba, y que no cree que aquel poco de espacio estuvo loco, sino que fingió la locura, como mañoso, astuto y sagaz, que debe ser (...), porque dice y refiere en sus confesiones y despues acá a echo casi todas las palabras que dijo estando con la fingida locura" (30).

También en este caso la Inquisición resolvió que el reo estaba cuerdo, en base a su habilidad argumentativa, errada mas coherente en sí misma (lejos estamos aún del concepto decimonónico de locura parcial, que podía afectar solo un área específica del entendimiento, dejando indemne el resto), aunque aquí sí debió respaldarse en la intervención médica para su diagnóstico. Por tal motivo, Fray De la Cruz terminó sus días en la hoguera, en 1578 (30).

El tercer proceso citado es el que siguió la Inquisición contra Ángela Carranza (Capítulo XXII de la "Historia"), quien "en quince años, escribió quince libros, compuestos de quinientos y quarenta y tres cuadernos, con mas de siete mil y quinientas foxas (...). Sus escritos, un seminario de heregias, errores, malsonancias, temeridades, escándalo de proposiciones cismáticas, impías, blasfemias peligrosas, arrogantes, presumptuosas, disparatadas, relaxativas de las costumbres, injuriosas y denigrativas de los próximos en todos estados" (30). El inquisidor Hoyo (citado por Ricardo Palma) declaró lo siguiente: "Este monstruo andaba en su casa como Eva en el Paraiso, y en los temblores salía sin cubrirse. (...) Y lo peor es que daba por pretesto à sus repetidos baños el ardor en que se abrasaba, originado del grande amor que tenia à Dios. Y luego ha sucedido que en un lugar sagrado intentó 
manosear á un hombre en partes á donde no se puede tocar sin culpa (...). En otra ocasion comunicándole una persona las tentaciones de carne que sufria, dijo la beata; ¡Ay! yo tambien las padezco ...... y añadio que el demonio la había hecho parir perritos" (36).

Tampoco "Ángela de Dios" -como se hizo llamarfue considerada loca por el Santo Oficio, pese a que otros procesados con extravagancias similares sí lo fueron. Para María Mannarelli aquello tuvo que ver con la amenaza que percibieron los inquisidores en la figura de Ángela, dada la gran influencia que llegó a tener no solo en el vulgo, sino también en la nobleza, "que la miraban y respetaban como a una de las mayores santas" (37). En efecto, era ella, "en la engañada aprehensión de los mortales, la santa de este siglo, la maravilla de este orbe, la maestra de la mística, la abogada del pueblo; milagros, éxtasis, raptos, inteligencias y revelaciones, se suponian tan frecuentes, que el cielo se juzgaba compendiado en aquella mujer" (30). Muchos coleccionaron "sus reliquias, sus muelas podridas, las uñas de sus dedos, sus piojos y zapatos viejos, ropa de su vestir desechada, y enaguas y mojaban en su sangre, cuando le picaban la vena, vendas y pañuelos" (37). De uno u otro modo, la beata se había identificado con otras "iluminadas", que buscaban un contacto directo con Dios, sin la intermediación de la Iglesia.

Semejante desafío al orden imperante no podía ocultarse solo declarando loca a la protagonista, había que destruir sus argumentos con el halo de la malignidad. Luego de 6 años de proceso, en 1694, Ángela "fué condenada a abjurar de levi i a cinco años de recojimiento, con prohibicion absoluta de tratar, escribir ni hablar con persona alguna acerca de revelaciones" (30). Podemos pensar que aquí se cumplió lo que afirma Hélène Tropé: "Ora valiéndose de la locura, ora descartándola, (los inquisidores) lograban su meta, que era asegurar a la Iglesia la exclusividad de la elaboración del discurso religioso e impedir cualquier forma de heterodoxia susceptible de poner en entredicho el orden político o religioso establecido" (32).

Otros procesados sí llegaron a ser considerados carentes de juicio, aunque no siempre pudieron librarse de la ejecución. Vemos los siguientes casos en la "Historia" de Medina: "Miguel Sanchez de Aguirre (...) habia dicho que 'juraba a Dios que mataria a Dios y al rey, y que no creya en Dios' (...) a la acusacion dixo que era verdad que habia dicho 'no creo en Dios', y que lo demas dixo estando loco, y presentó una informacion en esta raçon; (...) visto el negocio en consulta, paresció que se debía suspender, y assí se hizo" (Capítulo III). "Juan Fernandez de las Heras era un pobre loco a quien le habia entrado la manía de las cosas teolójicas, pero que no por eso se escapó de la hoguera" (Capítulo XIII). "Manuel Rodriguez, preso por judío, con secuestro de bienes, en el discurso de su causa estuvo como loco, i pretendiendo una noche escaparse, le metieron en un cepo. Puesto en el tormento, lo venció, siendo en definitiva absuelto de la instancia" (Capítulo XIV). "Juan Bautista del Castillo (...). En el Consejo se pidió la remision del proceso porque se pensó que el reo estaba loco, pero esta resolucion no pudo cumplirse por haber sido ya quemado cuando llegó a Lima" (Capítulo XV). "Enrique Jorge Tavares (...). Despues de varias revocaciones del reo, fué votado en 1639 a que se suspendiese su proceso por haber perdido la razon" (Capítulo XIX). "Manuel Henriquez (...) se tuvo sospecha de que estuviese loco, lo que no impidió que en 3 de julio de 1647 (...) fuese condenado a ser relajado, pena que no se habia ejecutado aun en 1656 por falta de ocasion" (Capítulo XIX). "Diego Martinez, natural de México, que decia que los jesuitas i frailes en jeneral no eran sacerdotes sino májicos, fué dado por loco" (Capítulo XIX). "Juan Ignacio de Atienza, (...) que se decia hijo de Felipe IV, profeta de Dios, que habia de ser pontífice, i que habia enjendrado hijos sin conocer a sus madres por un modo que llamaba per noctambulos, al fin fué dado por loco" (Capítulo XIX). (30)

\section{LA LOCURA VIRREINAL BAJO LA VISIÓN DE LA PSIQUIATRÍA}

En el Perú virreinal no hubo psiquiatría ni psiquiatras. El mismo término psychiaterie fue introducido por Johann Christian Reil recién en 1808, y no logró imponerse en Europa hasta la segunda mitad del siglo XIX (38). No fue solo cuestión de estrenar una palabra, se trataba de una nueva disciplina que requería de un lenguaje técnico propio para poder comprender y regular aquellas conductas y vivencias consideradas anormales o enfermas; tal lenguaje fue la psicopatología descriptiva, y se construyó a lo largo del siglo XIX (9,39). En el Perú solamente se puede hablar de una psiquiatría formal a partir del siglo $\mathrm{XX}$, pues previamente "solo tuvimos un alienismo discreto" (según Javier Mariátegui), y creemos que únicamente a ese alienismo le cabría con propiedad el calificativo de "protopsiquiatría", (que utiliza el mismo Mariátegui) (40). Tampoco el concepto actual de "enfermedad mental" estuvo presente en los tiempos 
coloniales, según se vio antes, y el cuidado de los insanos no era exclusividad de los médicos (y menos todavía de médicos "especialistas"), sino que muchas veces quedaba en manos de la familia o las órdenes religiosas. De modo pues que todo lo escrito acerca de la locura y los locos en los tiempos coloniales, desde una perspectiva psiquiátrica, ha sido elaborado mucho tiempo después de los hechos. Eso implica que se ha basado en aquella información que sobrevivió - que no es necesariamente toda la información que hubo- hasta llegar a las manos del psiquiatra historiador del siglo $\mathrm{XX}$, con la intermediación de cronistas, funcionarios, literatos o médicos, que a su vez interpretaron, resumieron $\mathrm{y}$ en ocasiones tradujeron las fuentes originales, imprimiendo ineludiblemente su propia visión del mundo en la versión final. Volveremos sobre esto más adelante.

Los primeros estudios histórico-psiquiátricos sobre la locura en los tiempos virreinales fueron hechos por Hermilio Valdizán. En su obra "Locos de la colonia", publicada entre 1918 y 1919 en los "Anales de la Facultad de Medicina" (41), el autor analiza datos de múltiples personajes que habitaron el Virreinato del Perú, para explicar su conducta bajo la terminología psiquiátrica, una forma abreviada de las "patografías" introducidas en la psiquiatría por Paul Möbius en la segunda mitad del siglo XIX (42). Este texto resulta de indudable valor histórico, no solo para aproximarse al pasado colonial peruano, sino sobre todo para conocer el pensamiento psiquiátrico de las primeras décadas del siglo XX. De este modo, el artículo de Valdizán está dividido en los siguientes capítulos: I - Las neurosis: histéricos y epilépticos; II - Las psicodisgenesias: Los frenasténicos; III - Las psicodisgenesias: Los locos morales; IV - Las psicodisgenesias: Los pervertidos sexuales; V - Las paratimias: Maniacos y melancólicos; VI - Las toxifrenias: Alcohólicos y embrujados; VII - Las demencias: Los seniles, los paralíticos, los precoces; VIII - Los místicos: Los sujetos; IX - Los místicos: Los endemoniados, y X Los místicos: El misticismo colectivo (41).

Algunos de los personajes presentados en las secciones anteriores aparecen en "Locos de la colonia". Por ejemplo, la enfermedad del Padre Becerra "invita a pensar en la psicosis maniaco-depresiva", por "el hecho de la alternabilidad de los períodos maniacos y melancólicos (...): hay en los referidos hechos de la enfermedad del religioso agustino una fase maniaca durante la cual el enfermo, verborreico y audaz, dice unas veces muy santas cosas y otras dice palabras que parecen por el maligno dictadas" (Capítulo V)
(41). En el caso de Juan de Villa, admite Valdizán la "imposibilidad de precisar la naturaleza de la agitación", por lo cual "hemos optado por concederle un sitio en este capítulo de las «Paratimias», en el cual hallan cabida la manía y la melancolía y también la llamada psicosis maniacodepresiva, entidad morbosa edificada sobre la base de dichos dos síndromas" (Capítulo V) (41). Recordemos que la denominación "psicosis maniaco-depresiva" había sido introducida por Emil Kraepelin en 1899, con antecedentes en la locura circular de Jules Falret, y la locura de doble forma de Jules Baillarger, ambas de 1854 (43).

El padecimiento del Padre Castrovi hizo a pensar a Valdizán en la demencia precoz, mas "sin insistir demasiado (...), limitándonos a una exposición de síntomas, hallamos en el Padre Castrovi un negativismo que autorizaba al Padre Calancha a decir que la locura de su hermano era callar y que se revelaba no sólo en esta forma fonética, si no en la probable de no tomar los alimentos cuando estos le eran ofrecidos (...). Es posible que aquel no alzar los ojos del suelo en uno y dos años, constituyera una estereotipia y es posible que a esta estereotipia de la expresión mímica, se agregase aquella de la expresión fonética, de interrumpir su mutismo para hablar del abandono contra conciencia de la doctrina de Paria" (41).

Es comprensible que el autor haya englobado bajo el mismo título los casos que consideró demencias seniles, demencias paralíticas y demencias precoces (Capítulo VII), tomando en cuenta que a principios del siglo XX el término "demencia" no estaba aún limitado por completo al deterioro senil irreversible, sino que incluía conceptos como la demencia vesánica, un estado de desorganización cognitiva que podía seguir a cualquier tipo de locura (44). La demencia precoz fue mencionada por Kraepelin en 1893, aunque el término ya había sido utilizado por Bénédict Morel y Arnold Pick años atrás, sin que hubiese una continuidad semántica entre ellos; del mismo modo, el paso de la demencia precoz hacia la esquizofrenia -término acuñado por Eugen Bleuler en 1911- no fue solo un cambio de palabras, sino una transformación conceptual (45). En cuanto a la demencia paralítica, el caso que presenta Valdizán como ilustrativo lo atribuye a una hemorragia, lo que es congruente con un concepto aún no restringido a la etiología luética para tal patología, a pesar del hallazgo de Hideyo Noguchi y John Moore en $1913(44,46)$, y aunque el mismo Valdizán había asociado la sífilis con la tabes y la ataxia locomotriz en otra parte de su libro (Capítulo I) (41). 
También cabe mencionar que Valdizán incluyó a la histeria y la epilepsia entre las neurosis (Capítulo I), lo que es compatible con una noción aún bastante amplia de neurosis, entendida como cualquier patología del sistema nervioso sin lesión localizada, y en una época previa al uso del electroencefalograma (inventado en 1924) para el diagnóstico de la epilepsia, que todavía formaba parte indiscutible de los trastornos psiquiátricos $(47,48)$.

Es de notar que el análisis incluye no solo a quienes fueron tomados por locos en su momento, sino adicionalmente a otros personajes que para la entonces moderna psiquiatría sí debían formar parte de su competencia, aun sin ser propiamente faltos de razón. Están en este grupo los "pervertidos sexuales" y los "locos morales", dos categorías diagnósticas impregnadas de la teoría degeneracionista, aún influyente a principios del siglo XX (49). Particularmente la "sodomía" recibe por parte de Valdizán comentarios que demuestran cuán tenues eran (¿son todavía?) las fronteras entre la moral y la medicina, entre el pecado y la patología: "aquella desgraciada inclinación, que antaño se dijo obra diabólica y hogaño es de los unos juzgada vicio y de los otros es juzgada, con más graves motivos, enfermedad" (Capítulo IV) (41). No está de más recordar que la homosexualidad como condición y "enfermedad" fue un invento del último tercio del siglo XIX, y a partir de la década de 1970 comenzó a ser retirada de las clasificaciones psiquiátricas internacionales $(50,51)$; una muestra del carácter cambiante de las taxonomías psiquiátricas, al cual se hará referencia más adelante.

Otros pasajes de "Locos de la colonia" corroboran la impronta degeneracionista. Por ejemplo, sobre el caso de Fray Diego Arce de Colchado (Capítulo III): "¿Hijos de qué matrimonio fueron estos desventurados? Tal vez el alcoholismo de los padres, la epilepsia o la imbecilidad de estos, pudieron ser la clave de las desdichas de esta familia de degenerados y explicarnos el castigo implacable de la naturaleza sobre tres seres que llevaron en sus venas una misma sangre" (41). En otra parte considera a doña Catalina de Erauzo (Capítulo III) "en el número de las víctimas de aquellas disgenesias del espíritu llamadas síndromes degenerativos y colocarla entre los locos morales" (41). La figura más representativa de la criminología del siglo XIX es citada directamente (Capítulo I): "Cesare Lombroso nos ha hablado del genio como de una sicósis degenerativa del grupo epiléptico" (41).
El espacio es corto para el examen minucioso que merecería el escrito de Valdizán. De todos modos cabe agregar que el "fundador de la psiquiatría peruana" (en palabras de Mariátegui) (52) es representativo de un momento histórico en el que se sentaron las bases para la psiquiatría en el Perú. Si bien desde mediados del siglo XIX existía un alienismo que había logrado fundar el Manicomio de Lima, la plena asimilación de la psiquiatría al seno de la medicina positivista se dio a inicios del siglo XX, como parte de un proceso que incluyó: la inauguración de la Cátedra de Enfermedades Nerviosas y Mentales de la Universidad de San Marcos, en 1917 (52); la apertura del Asilo Colonia de la Magdalena, en 1918 (3); la publicación del primer número de la Revista de Psiquiatría y Disciplinas Conexas, en 1918 (53), y la creación del Seminario Psico-Pedagógico, en 1919 (54). En tal contexto, el saber psiquiátrico buscó afirmarse, reinterpretando el pasado en los aspectos que asumió como propios, entre ellos justamente la historia de la locura (cabe recordar que antes de "Locos de la colonia", Valdizán había escrito "La alienación mental entre los primitivos peruanos", en 1915) (55).

Otro autor que se ocupó de la locura en los tiempos virreinales, desde la óptica psiquiátrica, fue Óscar Valdivia Ponce. En su minucioso y ampliamente documentado libro "Historia de la psiquiatría peruana", de 1964 (56), dedica varios capítulos al tema en mención, exponiendo el estado de la medicina, tanto en el Perú virreinal como en la España de aquel entonces. En 1989, Valdivia Ponce publicó "Panorama de la psiquiatría en el Perú: Volumen 1" (57), cuyo capítulo dedicado a los tiempos virreinales se diferencia muy poco de lo escrito 25 años antes (el Volumen 2 del "Panorama" salió a la luz en 1991, y no incluyó el tema del virreinato).

Al igual que Valdizán, Valdivia Ponce realiza aproximaciones diagnósticas de diversos personajes coloniales, en función a la nomenclatura psiquiátrica imperante, admitiendo que: "La característica patoplástica de los cuadros clínicos mentales refleja las inquietudes psicológicas y sociales de la época, sobresaliendo entre ellas las de tipo religioso" (56). Así, describe casos de complicaciones meningoencefálicas de la sífilis, trastornos mentales asociados a traumatismo encéfalo-craneano, síndromes cerebrales asociados a la ingestión de sustancias tóxicas, psicosis inducidas, trastornos mentales asociados a síndrome de la gran altura, epilepsia, trastornos endócrinos, trastornos derivados de alteraciones de las glándulas sexuales, neurosis, histeria, hipocondría, trastornos 
psicosomáticos, perversiones sexuales (aunque esto resultaba ya caduco en su "Panorama" de 1989), trastornos de la personalidad, trastornos psicóticos y psicosis situacionales (56).

Evita en lo posible Valdivia Ponce entrar en discrepancias con lo escrito antes por Valdizán, excepto sutilmente en algunos casos. Por ejemplo, los personajes incluidos dentro de la locura moral por el primero son reclasificados por el segundo autor como trastornos psicopáticos de la personalidad. Esto puede no ir más allá de una adecuación taxonómica, pero revela cómo el término "locura moral", nacido en 1835 con un significado diferente, llegó a identificarse a tal grado con la teoría de la degeneración de la segunda mitad del siglo XIX, que en la década de 1960 ya no tenía vigencia (58). Por su parte, el concepto de "personalidad psicopática" había sido introducido por Kraepelin en 1896, pero fue Kurt Schneider quien en 1923 le dio un significado afín al de "trastorno de la personalidad" (58). Otra diferencia con Valdizán la establece Valdivia Ponce al detectar una "depresión ansiosa" en la figura del conquistador Pedro Alcón (56), a quien el primero había diagnosticado un "síndroma maniaco", elucubrando inclusive la posibilidad de una "psicosis urémica" (Capítulo I) (41); como dato anecdótico, también Honorio Delgado había hablado de un "furioso ataque de manía" al referirse al mismo personaje (54).

En base a lo dicho al inicio de esta sección, resulta tentador tildar de anacrónico el uso que hace Valdivia Ponce de conceptos como "psiquiatría virreinal", "tratamientos psiquiátricos" o "psicoterapias" durante el virreinato. Pero debe tenerse en cuenta que hasta la década de 1960, imperaba en nuestro medio la historiografía médica tradicional, que no cuestionaba el carácter inmutable de los trastornos mentales, y por lo tanto no objetaba la existencia de un saber psiquiátrico ancestral, que podía rastrearse inclusive hasta los tiempos prehistóricos. Tal historiografía se caracterizó también por un enfoque panegirista o "heroico" de los "grandes hombres", y buscó legitimar científica y socialmente el conocimiento médico-psiquiátrico (59), a lo que se hizo alusión párrafos atrás al hablar sobre Valdizán y la psiquiatría de inicios del siglo XX. De ahí que otros historiadores también hayan intentado "rescatar atisbos perdidos de un pasado psiquiátrico oscuro (y mítico)" (en palabras de Germán Berrios) (60). Es a partir de la década de 1960 que surgirá una historiografía crítica -influida por las ideas de Michel Foucault, Gianbattista Vico, Otto Marx y otros autores-, que relativizará el conocimiento psiquiátrico y pondrá en duda el carácter esencial de los trastornos mentales $(59,60)$; esto cobrará suma relevancia en el tema de los diagnósticos restrospectivos, como se verá en la última sección.

Se ha hecho mención hasta aquí de los psiquiatras historiadores que abordaron en forma extensa el tema de la locura en la colonia. Muy brevemente habló Baltazar Caravedo Prado, en la década de 1930, de los "alienados" virreinales, clasificándolos como "histéricos, maníacos, melancólicos, epilépticos, oligofrénicos, intoxicados, esquizofrénicos, personalidades psicopáticas, y seniles" (61). Otros autores se han referido a personajes particulares para elaborar sus respectivas patografías. Tal es el caso de Lope de Aguirre, que fue estudiado prolijamente por Juan Lastres y Carlos Alberto Seguín, en una publicación de 1942. Basándose en los actos del conquistador ("inmisericorde, impulsivo, violento, feroz; no respeta la vida, la justicia ni el derecho; mata porque sí"), en su fisonomía (de "figura pequeña y contrahecha ... Pobre de cuerpo, bajo, delgado ... una figura miserable ... y una cara fea") e inclusive en la grafología de sus cartas, los autores llegan a la siguiente conclusión: "Tipo de constitución asténica, esquizoide anestésico, 'autista frío, impulsivo y activo'. Diagnóstico: Personalidad anormal, psicópata anafectivo", no sin antes dejar en claro que: “Era Aguirre un loco? El estudio de sus características y de su actuación nos permite negarlo" (62).

Se encuentra aquí también el concepto de personalidad psicopática, cuyos antecedentes históricos fueron explicados antes, y en tal sentido creen los autores necesario aclarar que: "Hoy se ha abandonado la noción de la locura moral como entidad nosológica, como enfermedad, noción difícilmente justificable desde el punto de vista psiquiátrico" (62). Asimismo, es interesante encontrar otras influencias teóricas en el ensayo. Por ejemplo, la teoría psicoanalítica es el referente utilizado para explicar la personalidad de Aguirre, lo que queda claro en la siguiente cita: "Lope de Aguirre es el segundón que proyecta, que transfiere, si queremos usar términos psicoanalíticos, los sentimientos que una infancia postergada frente al hermano mayor clavó en su espíritu, a todo lo que signifique autoridad, ley, regla, derecho" (62). O como en este otro, que rememora el asesinato de Pedro de Ursúa: "Los hombres feos se sienten heridos por los agraciados; es como si frente a éstos se hiciera más patente su fealdad, como si la belleza de los otros fuera un insulto a su propia ruindad estética" (62). Por otro lado, las hipótesis tipológicas de Ernst Kretschmer, 
que vinculan el aspecto físico con la personalidad, son mencionadas directamente para dar sustento a la descripción fisonómica de Aguirre. En general, entre los autores citados a lo largo del texto por Lastres y Seguín predominan notoriamente los de origen alemán, lo que refleja el claro prestigio que la psiquiatría germánica ostentaba en el Perú en la década de 1940.

Otro caso singular es el de Santa Rosa de Lima, quien en sus tiempos no parece haber sido considerada carente de juicio, ni tampoco fue mencionada por Valdizán ni Valdivia Ponce en sus obras, pero en los últimos años ha sido objeto de opiniones provenientes de la psiquiatría, que han dado lugar a diagnósticos tales como anorexia nerviosa $(63,64)$, paranoia mística (65), esquizofrenia, psicosis bipolar y trastorno de personalidad limítrofe (66). Tales especulaciones se basan principalmente en los martirios a los que se sometió en vida la santa limeña, en sus ayunos severos $\mathrm{y}$ en las visiones que dijo tener.

Y en efecto, al revisar datos biográficos de Santa Rosa, se hallan los siguientes testimonios de testigos que participaron en el proceso de canonización iniciado en 1617: “(...) parecía cosa sobrenatural y milagrosa que un cuerpo humano pudiese sustentar con tal abstinencia y ayuno (...). Y sabe que los días que comulgaba, en todo el día, no comía ni bebía; (...) y las veces que comía era a la noche, muy poco (...). Y esta testigo le oía cantar los días que no comulgó: De hambre me estoy cayendo. Y de sed me estoy secando. (...) (Tenía Rosa) una disciplina de hilo con unos cabalones (sic) de hierro, a manera de garfios, llena de sangre, con que la Santa se azotaba rigurosamente. (...) Se azotaba con cuenta (de) tantos azotes cada día y estos eran los que sus confesores le daban de licencia" (67). Al médico Juan del Castillo, le confesó Rosa "que algunas veces veía a Cristo Nuestro Señor (...) muy claro, aunque no todo el cuerpo mas que solo el rostro y el pecho", y otra testigo relató lo que le había contado Rosa cuando fue supuestamente atacada por el Demonio: "al momento sintió por las espaldas que se le llegaba una cosa que a ella le parecía, allá interiormente, que era como que tenía pelaje o salvaje y este se le largó encima de las espaldas y la empezó a abrumar y atormentar con grande extremo" (67).

Cabe preguntarse ahora: ¿con estos y otros datos parecidos se puede pensar que Santa Rosa de Lima tuvo esquizofrenia, anorexia u otro trastorno mental?

\section{EL PROBLEMA DE LOS DIAGNÓSTICOS PSIQUIÁTRICOS RETROSPECTIVOS}

Para que tenga sentido el ejercicio intelectual de adjudicar diagnósticos psiquiátricos actuales a figuras históricas, se debe necesariamente asumir como ciertas las siguientes premisas: 1) los trastornos mentales son entidades que existen naturalmente y permanecen inmutables a lo largo de la historia, más allá de cambios irrelevantes en las denominaciones; 2) el concepto de normalidad es también constante a lo largo de la historia y tampoco depende de cuestiones culturales, y 3) existen fuentes históricas fidedignas que representan "la verdad de los hechos". Veremos qué tan válidas son tales suposiciones.

La primera de aquellas premisas atribuye una naturaleza transhistórica y transcultural al diagnóstico psiquiátrico, y tiene congruencia con la visión biológica que impera en la psiquiatría contemporánea, para la cual un cerebro universal se manifiesta de idéntica manera en todo tiempo y lugar (68), lo que de hecho puede ser válido para los signos neurológicos, como las convulsiones y las parálisis. De este modo, no habría impedimento para establecer, por ejemplo, una analogía perfecta entre las visiones de las beatas coloniales y las que perciben los actuales pacientes con esquizofrenia; se asumen como iguales en esencia, aunque el contenido patoplástico pueda variar sin mayor trascendencia. Sin embargo, ignora esta perspectiva que las clasificaciones psiquiátricas han cambiado repetidas veces a lo largo de la historia -y nada hace pensar que no lo seguirán haciendo-, por razones no solo científicas sino también sociales, políticas y hasta económicas (por ejemplo, la influencia de la industria farmacéutica) (69). Esto es aplicable primordialmente a la psiquiatría, pero en menor medida también a toda la medicina (70). Los diagnósticos psiquiátricos, al fin y al cabo, son agrupaciones de ciertos comportamientos y vivencias subjetivas a los que llamamos síntomas mentales, y al ser éstos de naturaleza "híbrida" (en palabras de Berrios), dependen para su expresión de configuradores personales, familiares, sociales y culturales, así tengan un indudable asiento en el cerebro (39).

No se niega que pueda encontrarse cierta afinidad entre algunas condiciones del pasado y otras del presente (por ejemplo: las santas ayunadoras medievales, las jóvenes cloróticas del siglo XIX y las actuales anoréxicas, como señalan Weinberg y colaboradores) (64), pero eso no necesariamente establece una equivalencia ontológica. La búsqueda 
de tales paralelos exige cautela, más aun tratándose de personajes distantes en el tiempo, pues de otro modo se puede caer en la ilusión de la continuidad nosológica, basada en la creencia, sin fundamento sólido, en una "esencia" o "invariable" histórica $(10,69)$. Esta esencia suele ser descrita en términos biológicos (la "lesión cerebral", que se apoyó antes en la anatomía patológica y ahora en las neuroimágenes), pero también puede ser planteada psicológicamente. Por ejemplo, cuando se afirma que el supuesto trastorno mental de Santa Rosa tuvo como etiología un abuso sexual (66), se asume a priori que el concepto de "abuso sexual" y sus repercusiones psicológicas están exentas de influencias culturales y sociales, y por ende son aplicables tanto a personas del presente como a las del siglo XVI; ¿hay evidencia clara al respecto?

Las dificultades que implica el diagnóstico retrospectivo se traducen en la multiplicidad de etiquetas otorgadas a un mismo personaje a lo largo de la historia. Por ejemplo, desde el siglo XIX hasta el XXI, a Vincent Van Gogh le han descrito epilepsia (71), esquizofrenia (72), psicosis cicloide (73), trastorno bipolar (74), trastorno de personalidad limítrofe (75), intoxicación digitálica (76), saturnismo (77) y porfiria intermitente aguda (78). Más que ilustrar sobre "la verdadera enfermedad" que padeció tal o cual figura histórica, la evolución diacrónica de los diagnósticos puede dar luces sobre el contexto en el que se desenvolvieron los evaluadores (como vimos con Valdizán y Valdivia Ponce). En el caso concreto de los diagnósticos psiquiátricos, es bastante sabido que suelen tener una escasa confiabilidad (79); de ahí la pluralidad de diagnósticos dados a Santa Rosa por autores coetáneos (las fuentes que hemos encontrado abarcan un periodo de solo 13 años, entre 1999 y 2012) y presuntamente bajo la misma taxonomía.

Una forma habitual de evadir el anacronismo del diagnóstico psiquiátrico retrospectivo, es el recurrir a fórmulas contrafácticas como: "si fulano viviera hoy le diagnosticarían tal cosa y le recetarían tal otra". No obstante, dicho argumento cae en el yerro de concebir al individuo como un ente aislado de su entorno, omitiendo que la personalidad y los esquemas de pensamiento se forjan al amparo de un contexto social y cultural no extrapolable a otro. En palabras de Frank Graziano: "Rosa de Lima, como mística y santa, fue el resultado de interrelaciones complejas de su constitución individual (psicológica y corporal, con su interacción psicosomática); el contexto cultural formativo en el que fue educada, en el que actuó y en el que sus acciones fueron interpretadas, y la representación de su vida en el folklore, testimonios, hagiografía e iconografía, que exaltaron un ideal nupcial y penitencial de la santidad femenina" (80). Por lo dicho, no es factible una "Santa Rosa de Lima en el siglo XXI", pues cada quien es hija o hijo de su tiempo.

Esto lleva a la segunda premisa. Hemos leído a testigos que avalaron los tormentos y ayunos a los que se sometía Rosa, así como las visiones que dijo tener. Sin embargo, como fue dicho antes, no se conoce declaración alguna de contemporáneos suyos que interpretasen tales experiencias como señales de locura (67). Según Rubén Vargas Ugarte, en algún momento los confesores de la santa atribuyeron su vida espiritual a "vahidos de cabeza y a vapores de las semitas que comía" (81), pero no llegaron a un cuestionamiento serio de su cordura. Aunque quizás extremos, inclusive para la época, los suplicios autoinfligidos podían ser coherentes con el misticismo cristiano del siglo XVI. Lo expresó claramente Vargas Ugarte desde su óptica clerical: "El que ama a Jesús no puede menos de abrazarse con su cruz. Por eso Rosa vivió crucificada" (81). Para Moisés Lemlij, "en la religión católica hay una gran tradición de mortificación corporal como una forma de identificación con el sufrimiento de Cristo y como una manera de alcanzar la unión mística con Dios (...). De modo que santa Rosa no fue una loca que se flagelaba porque sí ni se inventó que para lograr la fusión con su objeto idealizado tenía que azotarse. Esto ya venía de mucho antes" (82). Por su parte, José del Busto afirma que Santa Rosa: "Careció de personalidad patológica. (...) Nunca perdió el sentido de la realidad. (...) En la mentalidad laica moderna hay alejamiento o desconocimiento de ciertas virtudes de la religión católica (...). Es aspecto humano casi no contemplado por los médicos y psicólogos, para quienes estas «rarezas» son propias de la patología mental" (67).

Si bien no es posible abogar con certeza a favor de la "salud mental" de Santa Rosa, pues tal actitud resultaría tan endeble como atribuirle diagnósticos psiquiátricos (al fin y al cabo, no nos consta su cordura ni su locura), resulta anacrónico ajustar las vidas de personajes de un pasado lejano a nociones contemporáneas de normalidad, convertidas en auténticos lechos de Procusto. Como acertadamente afirma Ramón Mujica: "No puedes usar categorías del siglo XX para analizar experiencias espirituales, religiosas o incluso psicológicas del siglo XVI. Debemos elevar nuestros niveles de referencia. Aprender a pensar con el otro, no sobre el otro" (83). 
Nos preguntamos en este punto: ¿sería legítimo utilizar diagnósticos como "manía lupina" o "locura furiosa" en pacientes del siglo XXI?

La tercera suposición tiene que ver con lo mencionado al inicio de la sección anterior. Decíase allí que la psiquiatría no ha podido tener acceso directo a los hechos virreinales, por lo que todas las especulaciones diagnósticas se basan en versiones indirectas. Es sabido que ningún historiador puede ser plenamente objetivo, pues en el proceso de selección de los datos, en la interpretación de los mismos y hasta en la traducción -cuando la hay- es inevitable una dosis de subjetividad (84). En el caso particular de Santa Rosa, por ejemplo, ha sido tema de debate por qué sus experiencias fueron prontamente aceptadas como meritorias de la santidad (su proceso de canonización se inició solo 8 días después de su muerte y culminó 54 años después), mientras que otras mujeres con relatos similares terminaron perseguidas por la Inquisición; probablemente en tal asunto hayan influido cuestiones políticas y sociales más que celestiales, lo que a su vez puede haber sesgado los testimonios que han llegado hasta el presente $(85,86)$. En palabras de Mujica: "estrictamente hablando, las hagiografías o vidas de los santos no son biografías históricas" (87).

Sobre Lope de Aguirre, Lastres y Seguín reconocen tres cartas como "la única documentación directa" a la que pudieron acceder, y sobre las otras fuentes expresan "qué poco podemos confiar en ellas" (62). Álvaro Baraibar hizo un estudio sobre la influencia de Francisco Vázquez -uno de los viajeros que escapó de Aguirre- en la construcción de la imagen negativa de "el Tirano" (88). Todo aquello obviamente no invalida el conocimiento que pueda surgir de tales fuentes, pero demanda prudencia antes de catalogar a alguien como enfermo mental, y más todavía al adjudicarle un diagnóstico preciso.

Debe recordarse finalmente que si bien algunos vocablos han sobrevivido al paso de los siglos, su significado ha ido mutando; lo hemos visto con los términos "melancolía" y "manía", por poner dos ejemplos. No tener esto en cuenta puede llevar a deslices tales como descubrir "trastorno bipolar" al leer descripciones de manía del siglo XVI.

Lo expuesto en estos últimos párrafos nos lleva a recomendar que la psiquiatría brinde mayor espacio a una visión más amplia y conocedora de las formas de pensamiento de otros tiempos, para que no incurra en el vicio de patologizar todo lo que no se ajuste a su marco epistemológico inmediato.

Agradecimiento: Al Profesor Germán E. Berrios, por sus valiosos comentarios y sugerencias.

\section{Correspondencia}

Santiago Stucchi-Portocarrero

Correo electrónico: santiago.stucchi.p@upch.pe

\section{REFERENCIAS BIBLIOGRÁFICAS}

1. Torres E. Buscando un rey. El autoritarismo en la historia del Perú, siglos XVI-XXI. Lima: Pontificia Universidad Católica del Perú; 2007.

2. Lastres JB. Historia de la medicina peruana. Volumen II: La medicina en el Virreinato. Lima: Universidad Nacional Mayor de San Marcos; 1951.

3. Stucchi S. Loquerías, manicomios y hospitales psiquiátricos de Lima. Lima: Universidad Peruana Cayetano Heredia; 2012.

4. Hampe T. Lexicografía y cultura: Diccionarios de lenguas europeas e indígenas en las bibliotecas del Perú colonial. Thesaurus. 1991; 46 (1): 16-42.

5. Cobarruvias S. Tesoro de la lengua castellana, o española. Madrid: Luis Sanchez impressor del Rey N.S.; 1611. (Citado el 1 de marzo del 2019). Disponible en: https://books.google.com.pe/books?i $\mathrm{d}=\mathrm{qKm}$ 8nzelynUC\&printsec $=$ frontcover\&hl=es\&so urce $=$ gbs_ge_summary_r $\&$ cad $=0 \# \mathrm{v}=$ onepage $\& \mathrm{q} \& \mathrm{f}=$ false

6. Real Academia Española. Diccionario de la Lengua Castellana. Madrid: Joaquin Ibarra, Impresor de Cámara de S.M.y de la RealAcademia; 1780. (Citado el 1 de marzo del 2019). Disponible en: https://books.google.com.pe/books?id= HhaAAAAYAAJ\&source=gbs_navlinks_s

7. Sacristán MC. Locura e Inquisición en Nueva España 1571-1760. Ciudad de México: El Colegio de Michoacán - Fondo de Cultura Económica; 1992.

8. Céard J. Entre lo natural y lo demoniaco: La locura en el Renacimiento. En: Postel J, Quétel C. Nueva historia de la psiquiatría. Ciudad de México: Fondo de Cultura Económica; 2000. p. 89-102.

9. Scull A. La locura: Una breve introducción. Madrid: Alianza Editorial; 2013.

10. Berrios GE. Cómo escribir una historia útil de la esquizofrenia. Vertex Rev Arg de Psiquiat. 2010; 21: 349-358.

11. Calancha A. Coronica moralizada del Orden de San Augustin en el Peru con sucesos egenplares en esta Monarquía. Barcelona: Pedro Lacavalleria en la Libreria; 1639. (Citado el 1 de marzo del 2019). Disponible en: http://bibliotecadigital.aecid.es/ bibliodig/es/consulta/registro.cmd?id=988 
12. San Agustín. Obras Tomo XVI. La Ciudad de Dios. Madrid: La Editorial Católica; 1958.

13. Santo Tomás de Aquino. Suma de Teología. Madrid: Biblioteca de Autores Cristianos; 1990.

14. Cervantes M. El ingenioso hidalgo Don Quijote de la Mancha (1605). Madrid: Alianza Editorial; 1984.

15. Burton R. The anatomy of melancholy, what it is: with all the kinds, causes, symptomes, prognostickes, and several cures of it. Oxford: Printed for Henry Cripps; 1638. (Citado el 1 de marzo del 2019). Disponible en: https://books.google.com.pe/books?id

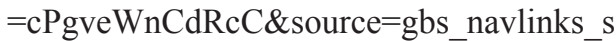

16. Farfán A. Tratado breve de mediçina, y de todas las enfermedades, que à cada passo se ofrecen. Mexico: Pedro Ochoorta; 1592. (Citado el 1 de marzo del 2019). Disponible en: http://www. bibliotecavirtualdeandalucia.es/catalogo/consulta/ registro. $\mathrm{cmd}$ ? $\mathrm{id}=7146$

17. Sacristán MC. Melancolía religiosa y culpabilidad en el México colonial. En: Bartra R (ed). Transgresión y melancolía en el México colonial. Ciudad de México: Universidad Nacional Autónoma de México; 2015. p. 37-51.

18. Luque R, Berrios G. Historia de los trastornos afectivos. Rev Colomb Psiquiat. 2011; 40: 130S-146S.

19. Trillat E. Trastorno de conversión e histeria: Sección clínica. En: Berrios GE, Porter R (eds). Una historia de la psiquiatría clínica. Madrid: Editorial Triacastela; 2012. p. 499-509.

20. Bermejo y Roldán F. Discurso de la enfermedad sarampión experimentada en la Ciudad de los Reyes del Perú. Lima: Por Joseph de Contreras y Alvarado; 1694. (Citado el 1 de marzo del 2019). Disponible en: https://archive.org/details/discursodelaenfe00berm

21. Melendez J. Tesoros verdaderos de las Yndias en la historia de la gran prouincia de San Iuan Bautista del Peru de el Orden de Predicadores. Roma: Imprenta de Nicolas Angel Tinassio; 1681. (Citado el 1 de marzo del 2019). Disponible en: http://bibliotecadigital. aecid.es/bibliodig/es/consulta/registro.cmd?id $=887$

22. Alarcón R. Historia de la psicología en el Perú. De la colonia a la república. Lima: Universidad Ricardo Palma; 2000.

23. Casalino C. Hipólito Unanue: el poder político, la ciencia ilustrada y la salud ambiental. Rev Peru Med Exp Salud Pública. 2008; 25 (4): 431-438.

24. Thimeo. Manias particulares. Mercurio Peruano. 1791; 1 (5): 38-40.

25. Stucchi L, Stucchi M. Navegar por los aires: Análisis físico y biológico del sistema propuesto por Santiago de Cárdenas en el siglo XVIII. Pendiente de publicación.

26. Cárdenas S. Nuebo sistema de Nabegar por los Aires sacado delas obserbaciones dla Naturalesa Bolatil [1762]. Lima: Imprenta Torres Aguirre; 1937.

27. Unanue H. Observaciones sobre el clima de Lima, y sus influencias en los seres organizados, en especial el hombre. Lima: Imprenta Real de los Huérfanos; 1806.

28. Hume D. Investigación sobre el conocimiento humano. Madrid: Editorial Biblioteca Nueva; 2002.

29. Alsinet J. Nuevo Método para curar flatos, hypocondria, vapores, y ataques hystéricos de las mugeres de todos estados y en todo estado, con el qual los enfermos podrán por sí cuidar de su salud en falta de Médico que les dirija. Madrid: Imprenta de Don Plácido Barco López; 1794. Versión facsimilar. Editorial Maxitor; 2010.

30. Medina JT. Historia del Tribunal del Santo Oficio de la Inquisición de Lima (1569-1820). Santiago: Imprenta Gutenberg; 1887. (Citado el 1 de marzo del 2019). Disponible en: http://bdh-rd.bne.es/viewer. vm?id $=0000037457$ \&page $=1$

31. Eymerico N. Manual de Inquisidores, para uso de las Inquisiones de España y Portugal, ó Compendio de la Obra titulada Directorio de Inquisidores. Mompeller: Imprenta de Feliz Aviñon; 1821. (Citado el 1 de marzo del 2019). Disponible en: https:// books.google.com.pe/books?id=T6BeAAAAcAAJ\& $\mathrm{dq}=$ Eymerico $+\mathrm{N} .+$ Manual $+\mathrm{de}+$ Inquisidores,+ para $+\mathrm{u}$ so + de + las + Inquisiones + de + Espa $\% C 3 \% B 1 a+y+$ Port ugal, $+\% \mathrm{C} 3 \% \mathrm{~B} 3+\mathrm{Compendio} \&$ source $=\mathrm{gbs}$ navlinks_s

32. Tropé H. Locura e inquisición en la España del siglo XVII. Norte de Salud Mental. 2010; 8 (36): 90-101.

33. Bartra R. Doce historias de melancolía en la Nueva España (Introducción). En: Bartra R(ed). Transgresión y melancolía en el México colonial. Ciudad de México: Universidad Nacional Autónoma de México; 2015. p. 11-36.

34. Cruz OM. Expresiones de la locura en el Virreinato de la Nueva Granada durante el siglo XVIII. Frenia. 2011; 11 (1): 47-66.

35. Hampe T. La gesta por la libertad de pensamiento: El caso del "hereje" francés Mateo Salado (siglo XVI). Acta Herediana. 2015; 56: 39-50.

36. Palma R. Anales de la inquisición de Lima. (Estudio histórico). Lima: Tipografía de Aurelio Alfaro; 1863. (Citado el 1 de marzo del 2019). Disponible en: https://books.google.com.pe/books?id=wfkCAAAA YAAJ\&source $=$ gbs_navlinks_s

37. Mannarelli ME. Hechiceras, beatas y expósitas: Mujeres y poder Inquisitorial en Lima. Lima: Ediciones del Congreso del Perú; 1999.

38. Marneros A. Psychiatry's 200th birthday. Br J Psychiatry. 2008; 193 (1):1-3.

39. Berrios GE. Hacia una nueva epistemología de la psiquiatría. Buenos Aires; Editorial Polemos; 2011.

40. Mariátegui J. La psiquiatría peruana: Presente y futuro. Rev Neuropsiquiatr. 1999; 62 (1): 3-13.

41. Valdizán H. Locos de la colonia. Anales de la Facultad de Medicina de Lima. 1918; 1: 169-185. 1918; 2: 
128-140, 173-195. 1919; 3: 25-41, 71-92, 198-218. 1919; 4: 64-80.

42. Schiller F. A Möbius Strip: Fin-de-siècle Neuropsychiatry and Paul Möbius. Berkeley: University of California Press; 1982.

43. Postel J. La demencia precoz y la psicosis maniacodepresiva. Kraepelin. En: Postel J, Quétel C. Nueva historia de la psiquiatría. Ciudad de México: Fondo de Cultura Económica; 2000. p. 217-224.

44. Berrios GE. Demencia: Sección clínica. En: Berrios GE, Porter R (eds). Una historia de la psiquiatría clínica. Madrid: Editorial Triacastela; 2012. p. 51-70.

45. Hoenig J. Esquizofrenia: Sección clínica. En: Berrios GE, Porter R (eds). Una historia de la psiquiatría clínica. Madrid: Editorial Triacastela; 2012. p. 391405.

46. Postel J. La parálisis general. En: Postel J, Quétel C. Nueva historia de la psiquiatría. Ciudad de México: Fondo de Cultura Económica; 2000. p. 198-208.

47. Bancaud J. La epilepsia antes del descubrimiento del electroencefalograma. En: Postel J, Quétel C. Nueva historia de la psiquiatría. Ciudad de México: Fondo de Cultura Económica; 2000. p. 247-254.

48. Berrios GE. Epilepsia: Sección clínica. En: Berrios GE, Porter R (eds). Una historia de la psiquiatría clínica. Madrid: Editorial Triacastela; 2012. p. 181197.

49. Bing F. La teoría de la degenerescencia. En: Postel J, Quétel C. Nueva historia de la psiquiatría. Ciudad de México: Fondo de Cultura Económica; 2000. p. 225-229.

50 . Katz JN. The invention of heterosexuality. Socialist Review. 1990; 20 (1): 7-34.

51. Lyons RD. Psychiatrists, in a shift, declare homosexuality no mental illness. New York: The New York Times; December 16, 1973. (Citado el 1 marzo del 2019). Disponible en: https://www. nytimes.com/1973/12/16/archives/psychiatrists-in-ashift-declare-homosexuality-no-mental-illness.html

52. Mariátegui J. Hermilio Valdizán: El proyecto de una psiquiatría peruana. Lima: Biblioteca de Psiquiatría Peruana; 1981.

53. Stucchi S. Cien años de la Revista de Psiquiatría y Disciplinas Conexas. Rev Neuropsiquiatr. 2018; 81 (4): 270-278. DOI: https://doi.org/10.20453/rnp. v81i4.3442

54. Delgado H. La psiquiatría y la higiene mental en el Perú. Anales de la Facultad de Ciencias Médicas. 1936; 19 (1): 103-122.

55. Valdizán H. La alienación mental entre los primitivos peruanos. Tesis del doctorado. Lima: Universidad Mayor de San Marcos, Facultad de Medicina; 1915.

56. Valdivia Ó. Historia de la psiquiatría peruana. Lima: Gráfica Morsom; 1964.

57. Valdivia Ó. Panorama de la psiquiatría en el Perú. Volumen 1. Lima: Universidad Nacional Mayor de
San Marcos; 1989.

58. Sass H, Herpertz S. Trastornos de la personalidad: Sección clínica. En: Berrios GE, Porter R (eds). Una historia de la psiquiatría clínica. Madrid: Editorial Triacastela; 2012. p. 733-746.

59. Huertas R. Historia de la psiquiatría, ¿por qué?, ¿para qué? Tradiciones historiográficas y nuevas tendencias. Frenia. 2001; 1 (1): 9-36.

60. Berrios GE. Historia de los síntomas de los trastornos mentales. La psicopatología descriptiva desde el siglo XIX. Ciudad de México: Fondo de Cultura Económica; 2008.

61. Caravedo B. La locura en el incario y en la colonia. En: Caravedo B, Ortiz de Zevallos P (editores). La reforma psiquiátrica en el Perú. Lima: Clínica Baltazar Caravedo; 1985. p. 25-30.

62. Lastres JB, Seguín CA. Lope de Aguirre, el rebelde. Estudio histórico - psicológico. Buenos Aires: Librería y Editorial "El Ateneo"; 1942.

63. Behar R. Santa Rosa de Lima: un análisis psicosocial de la anorexia nerviosa. Rev Psiquiatr Chil. 1991; 8: 707-711.

64. Weinberg C, Cordas TA, Albornoz P. Santa Rosa de Lima: uma santa anoréxica na América Latina? Rev Psiquiatr RS. 2005; 27 (1): 51-56.

65. De Paz M. Santa Rosa y la espina de la locura. Lima: Caretas; 29 de agosto del 2012. p. 52-55.

66. Anónimo. Santa Loca de Lima. Lima: Dedomedio. 2009; 3 (24): 34-35.

67. Del Busto JA. Santa Rosa de Lima. Lima: Pontificia Universidad Católica del Perú; 2016.

68. Suárez R. El concepto genio es de los más dañinos de la historia de la ciencia, siempre es un equipo: Germán Berrios psiquiatra y catedrático de la Universidad de Cambridge. Vigo: Atlantico; 1 de octubre del 2018 (Citado el 1 marzo del 2019). Disponible en: http://www.atlantico.net/articulo/ vigo/concepto-genio-es-mas-daninos-historiaciencia-siempre-es-equipo/20180930231139670785. $\mathrm{html}$

69. Kendler KS. The nature of psychiatric disorders. World Psychiatry. 2016; 15 (1): 5-12.

70. Karenberg A. Retrospective diagnosis: Use and abuse in medical historiography. Prague Medical Report. 2009; 110 (2): 140-145.

71. Vallejo-Nágera JA. Locos egregios. Barcelona: Editorial Planeta; 1989.

72. Jaspers K. Genio artístico y locura: Strindberg y Van Gogh. Barcelona: El Acantilado; 2001.

73. Strik WK. La enfermedad psíquica de Vincent van Gogh. Alcmeon. Revista Argentina de Clínica Neuropsiquiátrica. 1996; 4: 0-0. (Citado el 1 marzo del 2019). Disponible en: http://www.alcmeon.com. ar/5/19/a19_07.htm

74. Perry I. Vincent van Gogh's illness: a case record. Bulletin of the History of Medicine. 1947; 47: 146- 
172.

75. Van Meekeren E, Gunderson JG. Starry Starry Night: Life and Psychiatric History of Vincent van Gogh. Amsterdam: Benecke NI; 2003.

76. Lee TC. Van Gogh's vision: Digitalis intoxication? JAMA. 1981; 245 (7): 727-729.

77. González FJ, Montejo AL. Vincent Van Gogh, poseído por el color y la luz. Salamanca: Laboratorios Juste SAQF; 1997.

78. Arnold WN. The illness of Vincent van Gogh. J Hist Neurosci. 2004; 13 (1): 22-43.

79. Aboraya A, Rankin E, France C, El-Missiry A, John C. The reliability of psychiatric diagnosis revisited: The Clinician's Guide to Improve the Reliability of Psychiatric Diagnosis. Psychiatry (Edgmont). 2006; 3 (1): 41-50.

80. Graziano F. Wounds of love: The mystical marriage of Saint Rose of Lima. New York: Oxford University Press; 2004.

81. Vargas R. Vida de Santa Rosa de Lima. Buenos Aires: Imprenta López; 1961.

82. Miyagi A. Isabel Flores de Oliva: la rosa o la espina. Lima: El Comercio. Suplemento El Dominical; 29 de agosto del 2018. (Citado el 1 marzo del 2019).

Disponible en: https://elcomercio.pe/eldominical/ isabel-flores-oliva-rosa-espina-noticia-451361
83. De Paz M. Ramón Mujica: "Nadie me va a hacer creer que Santa Rosa debería estar en el Larco Herrera". Lima: El Comercio; 22 de agosto del 2017. (Citado el 1 marzo del 2019). Disponible en: https:// elcomercio.pe/luces/arte/ramon-mujica-nadie-mecreer-santa-rosa-deberia-larco-herreranoticia-451948

84. Carr EH. ¿Qué es la historia? Ciudad de México: Editorial Planeta De Agostini; 1985.

85. Hampe T. Los testigos de Santa Rosa. (Una aproximación social a la identidad criolla en el Perú Colonial). Revista Complutense de Historia de América. 1997; 23: 113-136.

86. Graziano F. Santa Rosa de Lima y la política de la canonización. Revista Andina. 2002; 34: 9-39.

87. Mujica R. Santa Rosa de Lima y la política de la santidad americana. Perú: indígena $\mathrm{y}$ virreinal. Barcelona: Museu Nacional d'Art de Catalunya; 2005.p. 96-101.

88. Baraibar Á. Lope de Aguirre: La construcción de una imagen del poder. Alpha. Revista de artes, letras y filosofía. 2011; 33: 187-200.

Recibido: 21/02/2019

Aceptado: 08/03/2019 